\title{
Towards improving the Performance of the Weak Students through Identification and Effective Implementation of Tasks by the Quality Circle
}

\author{
Dr. U M Daivagna ${ }^{1 *}$, S B Yapalaparvi ${ }^{2}$, D N Inaamadar ${ }^{3}$, N K Honnagoudar ${ }^{4}$ \\ $1^{*}$ Corresponding Author, Professor in Mechanical \\ Engineering, Hirasugar Institute of Technology, \\ Nidasoshi.,Tq;Hukkeri,Dist.Belagavi,State.Karnataka,. \\ India.Pin:591236, \\ 2 Assistant Professor and H.O.D in Mechanical \\ Engineering, Hirasugar Institute of Technology, \\ Nidasoshi. \\ $3 \& 4$ Assistant Professors in Mechanical engineering, \\ Electronics and Communication Engineering, Hirasugar \\ Institute of Technology, Nidasoshi. \\ Email:1daivagnaum@gmail.com \\ 12daivagnaum@gmail.com
}

\begin{abstract}
:
In this paper the weak students are identified by Pareto analysis, the cause and effect diagrams are drawn for the critical subjects and weak students. The treatment of weak students is carried out by formation of quality circle. The faculties and instructors are the members and one of the senior faculties is the leader. In the Quality Circle meetings, they take strategies to improve the performance of weak students. The process involves guiding, monitoring assignment submissions, counseling, evaluation etc. The weak students are also taught by taking micro classes and motivated ethically through great people quotes. The examination tips along with the activities to be followed during academic study are stressed.
\end{abstract}

Key Words: Pareto analysis, weak performed students, engineering, analytical subjects, group leader, and recording of submissions

\section{Dr. U M Daivagna ${ }^{1}$}

Professor in Mechanical Engineering, Hirasugar Institute of Technology,

Nidasoshi.,Tq;Hukkeri,Dist.Belagavi,State.Karnataka,. India.Pin:591236

\subsection{Introduction}

One has to look over the sentence "Students Life is a Golden life". In ancient system of education system in India Gurukulas were educating.

Throughout the centuries and from past two decades of this century in education system, there are lots of changes occurred. Now a day's student centered learning getting more and more importance.

The students entering into engineering field were taught basic subjects like mathematics, physics and chemistry during pre-university education. There are several categories of students starting from bright to average. The students who are just qualified enter into engineering field; many of them rectified their pattern of study habits and achieve good results in their career due to 
their hard nature of working. But most of the students do not overcome the inertia in their study pattern. It may be due to not understanding the subjects, not having grasping power, language problem, rich financial positions of the family, environmental problems, food, residence, not having responsibility from family side, entertainment facilities, mobiles, internet, not attending classes, self fear and not to ask anything to faculties, a bad friends circle, not interested in the field and many more.

Many subjects in engineering include theory, derivations through analytical equations, sketches, photographs, diagrams, block diagrams, principles, mechanisms, machines, electronic devices, circuits, logics, algorithms, software programs and technologies, designing of components, processes of manufacture, materials and their structures, programming languages, software's, etc.

Some subjects involve theory oriented, understanding of these require less efforts by the students. The theory subjects are easy to understand On the other hand some subjects require analytical ability to derive equations, remembrance of formulae, procedure of solving problems, definite steps in the solution, understanding the diagrams, concepts, principles, programming ability, definitions, empirical relations, logics, ideas etc. These subjects not only require technical skills but also require thorough knowledge in the subject. Hence hard work and sincerity in studying these is the only substitute to achieve success.

The objective of this paper is to drag the attention of both teaching and non-teaching to identify the weak students in each semester of their department and involve more with weak students to uplift in their knowledge to achieve improvement in both academically as well as in their career. The following topics in relation to this paper are;

- To identify weak students after first internal test

- $\quad$ To form the group and group leader to implement strategies to improve weak students performance

- The group responsibilities and tasks
- $\quad$ Counseling of weak students along with parents

- To record the submissions of students in the process

- Overall monitoring of weak students regarding attendance and academic studies

Thus the paper involves in identification of weak performed students and the treatments to be given with coordination and cooperation of the staff and the weak students to achieve good academic results.

\subsection{Literature Review}

Hilary Coon, Gregory Carey, David W. Fulker, J .C. Defries [1] discussed about the effects of school environment on the performance of students. R.M. Felder, G.N. Felder, E.J. Dietz [2] had presented the effects of personality type on engineering student performance and attitudes. Hermino Rodriguez Principe [3] studied the factors influencing the students for academic performance in the first accounting course and highlighted the importance of the internal and external class-room parameters.

Cristina Pomales-García, Yili Liu [4] had studied the views and perceptions of engineering undergraduate students on engineering education and used the method of content analysis to analyze the language used by engineering undergraduate students to extract the underlying common factors or perceived characteristics of "Excellence in Engineering Education". M.S. Farooq A.H. Chaudhary, M. Shafiq and G. Berhanu [5] conducted a study to examine different factors influencing the academic performance of secondary school students in a metropolitan city of Pakistan. The results of the study revealed that socio-economic status (SES) and parents' education have a significant effect on students' overall academic achievement as well as achievement in the subjects of Mathematics and English. It was found that girls perform better than the male students. 
Victor Lavy and Edith Sand [6] estimated the influence of social relationships on educational attainment and social outcomes of students in school and identified reciprocal friends (students who list one another); followers (those who listed fellow students as friends but were not listed as friends by these same fellow students) and (3) non-reciprocal friends (parallel to followers) and also suggested that the presence of reciprocal friends and followers in class has a positive and significant effect on test scores in English, math, and Hebrew. Irfan Mushtaq and Shabana Nawaz Khan [7] focused their research on student performance in intermediate examination and it is linked with students' outline consisted of his approach towards communication, learningfacilities, proper guidance and family stress based on the data of private college.

Dr. V.P.Gosavi [8] described the present scenario and vacancy position trend of engineering educational institutions in India. Though the private institutes have grown in number they have failed in maintaining expected quality. They are not able to attract the high ranking students, hence are denied by the majority stake holders. This means that there is direct need of the Private Engineering Colleges to cater this need but they must maintain the desire quality and contribute in producing quality Engineers.

Pimpa Cheewaprakobkit [9] analyzed the factors affecting academic achievement that contribute to the prediction of students' academic performance and it was useful in identifying weak students who are likely to perform poorly in their studies. Regina A. Garcia and Lilac A. Al-Safadi [10] used Intervention strategies which are the systematic instructions to promote progress. Jai Ruby and Dr. K. David [11] used Multi Layer Perception algorithm to analyze the students' academic performance.

\subsection{Study Process}

In engineering education there are eight semesters in almost all braches. Each semester consists of at least five subjects and two laboratories. Each subject is having 25 marks for internal assessment and 100 marks for theory examination. To pass examination the student has to acquire 50 out of 125 marks. Some of the subjects are theoretical in nature and some are analytical based. The internal assessment tests will be based on the average of best two tests. Usually three tests are conducted. Fig.1 shows the various factors inclusive of health.

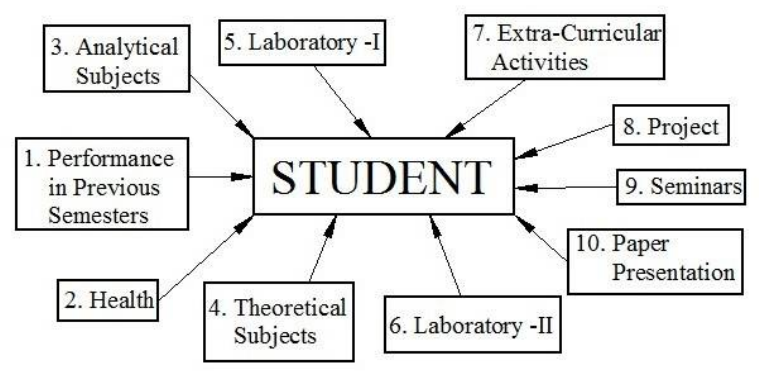

Fig.1 Academic factors that are acting on student activities during each sem ester

The Fig. 2 shows environmental, residential, study management etc which affect the performance during academic semester. The following paragraphs illustrate the identification of critical subjects in each semester and identification of weak students.

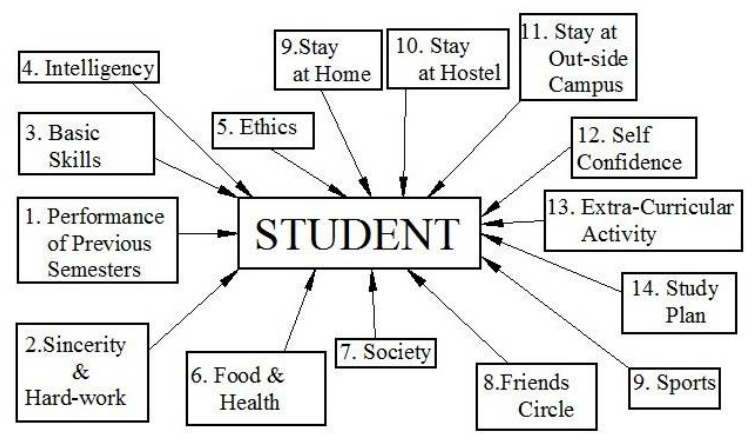

Fig.2 Block Diagram showing Academic \& Environmental Factors which affect Student perform ance

\subsection{Identification of Critical subjects though Pareto} Analysis 
The Pareto analysis [12] is carried out to identify the critical subjects after first Internal Assessment Test. For example, the following Pareto analysis is made based on the first internal test for $\mathrm{V}$ semester $\mathrm{E} \& \mathrm{C}$ and $\mathrm{V}$ semester Mechanical. The Pareto analysis is shown Fig.3 and Fig.4 respectively for mechanical and $\mathrm{E} \& \mathrm{C}$ students.

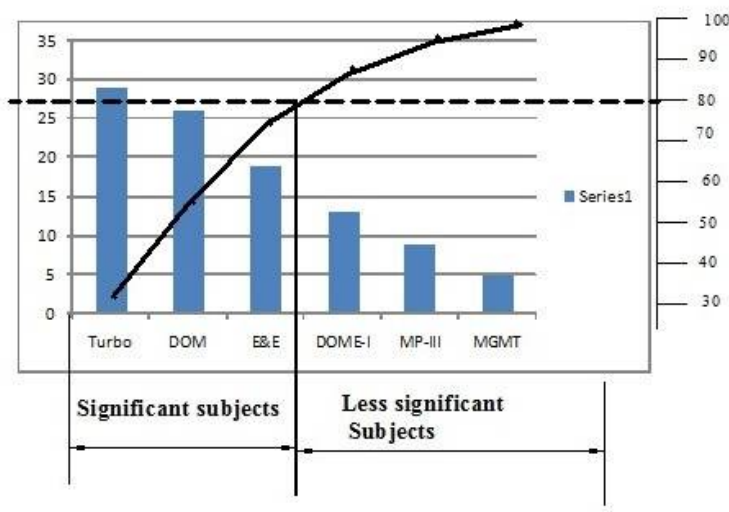

Fig.3 Pareto Analysis of V sem BE Mechanical

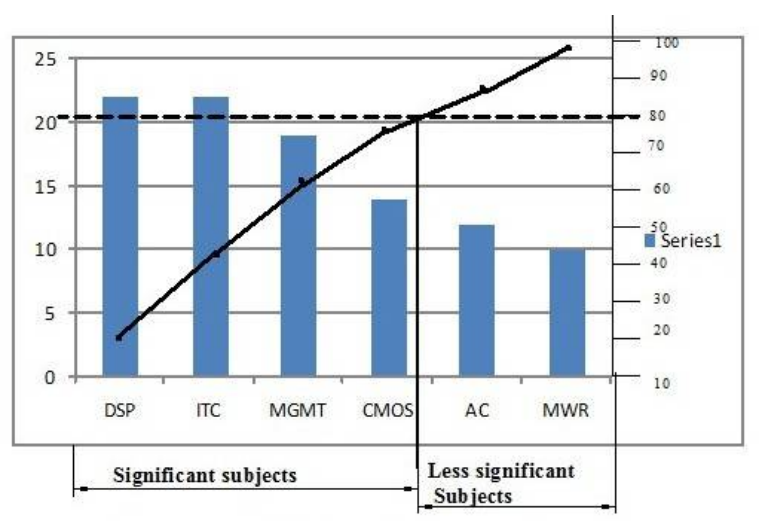

Fig.4 Pareto Analysis of V sem BE E\&C

The student who scores below 10 is identified as weak student. The weak students are identified after first internal test.

The critical subjects of $\mathrm{V}$ Semester Mechanical are Turbo Machine, Dynamics of Machinery and Energy Engineering. Similarly for Semester E\&C the critical subjects are Digital Signal Processing, Information and Coding and Management

\section{Cause and Effect Diagrams}

Ishikawa cause and effect diagrams [13] for weak student and also towards the achievement of improved performance are shown in Fig.5 and Fig.6 respectively.

The members of the Quality Circle include Faculties and Instructors who handle laboratories. Firstly, the formation of the committee should be assigned to a group leader of the particular class. Senior faculty may be treated as group leader. The leader can call meetings and fix up the strategies to be applied for the improvement of weak students. The instructors can take keen interest to actively participate in the process to collect solutions, assigned work and incase of counseling etc and assist in successfully implementation of the Quality circle strategies.

Once in fifteen days a meeting may be conducted regarding to check the submissions of students assignments, solutions to problems of internal assessments etc. The weak students shall be counseled for his lack of knowledge in each subject. The respective faculty may guide them by providing notes, text books, pdf files, ppts and even video CDS' etc. The faculty may send e-notes through emails.

\section{Quality Circle Duties}

- Formation of committee

- Conduct first meeting after Internal Test-I

- Discuss with members and take decision regarding strategies to be applied

- Instructors are to be directed to collect the submissions of weak students during their Labhours or in slack time

- Call parents for the counseling of the weak students and plan strategies to improve the performance

- Advise the weak students to perform well and take them to confidence

- Record the submissions, parent meeting etc

\section{Planning of Analytical Subjects}

\section{JeË.}


Each student has to take first course plan i.e., the content of each subject. Each subject consists of 8 chapters. Each chapter deals with theory, derivations, problems and solutions. The following parameters will affect students' performance during each semester.

- Regularity in attending classes

- $\quad$ Taking notes and grasping

- Analyzing the technical reasons while solving problems

- Doing home assignments

- Collection of Text and Reference Books

- Developing capability to solve exercise and examination problems without help of others

The regular attendance along with skills of grasping technical skills, reasoning, home assignments, and problem solving techniques will enhance students' performance.

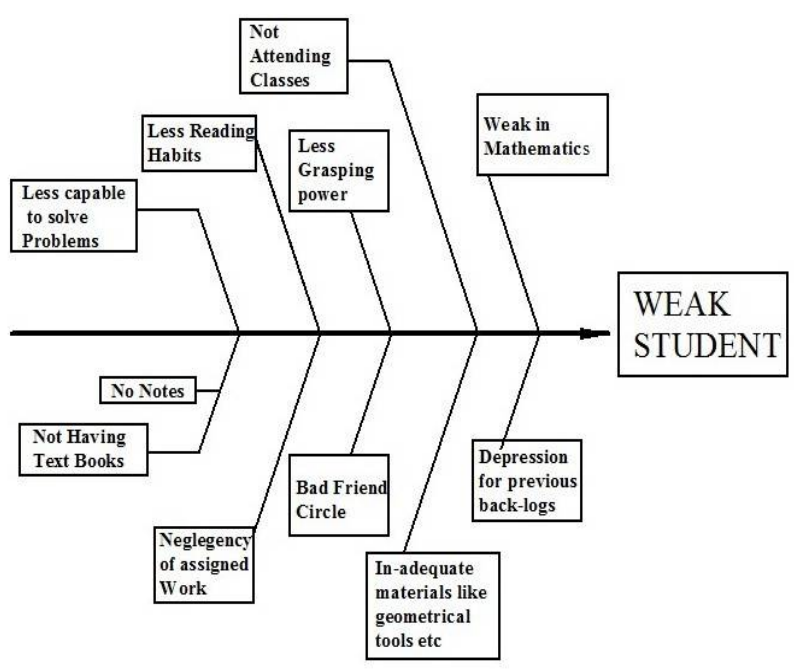

Fig.5 Cause and effect diagram of a weak student



Fig.5 Cause and effect diagram for improved performance

\subsection{Planning:}

The students must plan and execute for the following.

- To get syllabus and course of study

- To get text and reference books, lecture notes, pdf or PPTs or video CDs

- To get sufficient rough papers, note books, geometrical instruments etc.

- To involve in home assignments

- To collect minimum 3 years question papers with solutions

\section{Dos' and don't dos' of students, advantages and some useful examination tips}

Following are some of the Dos' and Don't Dos' of students during academic.

\subsection{Dos' of students}

- Attend regular classes and respect your faculty

- At least one can know the difficulties in each subject by attending classes

- Do solve the problems which are already solved in class

- Try to solve on your own the problems and then compare the results

- Keep one Text Book with you, solve all exercise problems on each topic along with examination problems

- Write formulae and important data on one sheet for each topic

- Remember, and recall all motivating factors to understand more and more

- Keep all problems with solutions along with derivations, theory part for each subject for ready reference 
- Contact faculty with request and humble to get your work done.

\subsection{Don't Do these:}

- Don't skip classes

- Don't spend time unnecessarily

- Don't involve in such activities which irritate faculty and staff

- Don't behave rude and rough

- Don't wander here and there unnecessarily

- Don't shout rudely in campus

- Don't try to cheat in examination/tests

- Don't use harsh words for any one

- Don't keep books, notes here and there

- Don't ask any material or geometrical instruments during test/examination

- Don't use un-clean dresses

- Don't involve in criticizing others for some or small mistakes

- Don't be away from ethics or ethical standards

\subsection{Advantages of the process proposed}

- Weak students get benefited

- $\quad$ Parents will be happy

- Since weak students are identified early they get ample time to recover

- Weak students may develop competency in achieving good results because of motivation and support

- Students and Teacher relationship will be in very good harmony

\subsection{Examination Tips}

- Utilize time effectively to solve all problems

- If the examination duration if 3hours then the time available for each question carries 40 minutes
- Some questions take less time and some take more time, hence utilize time factor judiciously

- Attend easy and well known answers first and then give priority to solve other

- Even if you solve few questions answer them $100 \%$ correctly

- Be calm and quiet before examination

- Maintain good health during examination period

\section{Conclusions}

Through the Pareto analysis critical subjects of each semester are determined and also weak students are identified on the basis of marks scored in first internal test. The Quality Circle will be proposed by using the faculties of the same class along with laboratory instructors. The counseling of weak students makes them to habitulize in contacting the faculty with more interest and enthusiasm. The cause and effect diagrams will depict the actions and treatment to be taken during Quality Circle meetings. After the first test lot of time will be available for the weak students to rectify their problems in understanding of the critical subjects. Thus the efforts are put by the authors in diagnosing the weak students and treatment process towards the improvement of weak students.

\section{Acknowledgement}

The authors are faculties of Hirasugar Institute of Technology, Nidasoshi and very much thankful to the Principal, Head of the Departments, Staff and Management to bring this paper.

\section{References}

1 Hilary Coon ,Gregory Carey,David W. Fulker,J .C. Defries, University of Utah and University of Colorado, Boulder, "Influences of School Environment on the Academic Achievement Scores of Adopted and No adopted Children, INTELLIGENCE 17,1993, pp 79-104.

2. R.M. Felder, G.N Felder, E.J. Dietz, "The Effects of Personality Type on Engineering Student Performance and Attitudes", Journal of Engineering Education, 91(1), 2002, pp.3-17. 
3. Hermino Rodriguez Principe, "Factors influencing the students' academic performance in the first accounting course; a comparative study between public and private Universities in Puerto Rico", PhD Thesis, Nov 2005, pp 1257

4. Cristina Pomales-García, Yili Liu, "Excellence in Engineering Education: Views of Undergraduate Engineering Students', Journal of Engineering Education, July 2007, 252-262pp.

5. M.S. Farooq A.H. Chaudhary, M. Shafiq and G. Berhanu, "Factors Affecting Students' Quality of Academic Performance: A Case of Secondary School Level" Journal of Quality and Technology Management, Vol.VII, Issue II, Dec 2011, pp 1-14.

6. Victor Lavy and Edith Sand," The Friends Factor: How Students' Social Networks affect Their Academic Achievement and Well-Being?" National Bureau of Economic Research, 1050 Massachusetts Avenue Cambridge, MA 02138, October 2012.

7. Irfan Mushtaq and Shabana Nawaz Khan, "Factors Affecting Students' Academic Performance", Global Journal of Management and Business research, Vol.12, Issue 9, June 2012, Online ISSN: 2249-4588, pp 1-7.

8. Dr. V.P.Gosavi," Threat of Vacant Seats in Engineering Colleges: Reasons and Remedies", American International Journal of Research in Humanities, Arts and Social Sciences, 2(1), March-May, 2013, pp. 75-80.

9. Pimpa Cheewaprakobkit, "Study of Factors Analysis Affecting Academic Achievement of Undergraduate Students in International Program", Proceedings of the International Multi Conference of Engineers and Computer Scientists 2013 Vol. I, IMECS 2013, March 13 - 15, 2013, Hong Kong, ISSN: 2078-0966 (Online), pp1-5

10.Regina A. Garcia and Lilac A. Al-Safadi," Intervention Strategies for the Improvement of Students' Academic Performance in Data Structure Course", International Journal of Information and Education Technology, Vol. 4, No. 5, October 2014,pp383-387.

11. Jai Ruby and Dr. K. David," Analysis of Influencing Factors in Predicting Students Performance Using MLP-A Comparative Study", International Journal of Innovative Research in Computer and Communication Engineering (An ISO 3297: 2007 Certified Organization), Vol. 3, Issue 2, February 2015, ISSN (Online): 2320-9801, pp 10851092.

12.http://www.ghd.com/pdf/6.\%20Pareto\%20Analysis.pdf
13.https://en.wikipedia.org/wiki/Ishikawa_diagram 